\title{
Tantalum-based diffusion barriers in Si/Cu VLSI metallizations
}

\author{
E. Kolawa, J. S. Chen, J. S. Reid, P. J. Pokela, and M.-A. Nicolet \\ California Institute of Technology, Pasadena, California 91125
}

(Received 22 February 1991; accepted for publication 19 April 1991)

\begin{abstract}
We have studied sputter-deposited Ta, Ta ${ }_{36} \mathrm{Si}_{14}$, and $\mathrm{Ta}_{36} \mathrm{Si}_{14} \mathrm{~N}_{50}$ thin films as diffusion barriers between Cu overlayers and Si substrates. Electrical measurements on $\mathrm{Si} n^{+} p$ shallow junction diodes demonstrate that a 180 -nm-thick Ta film is not an effective diffusion barrier. For the standard test of 30-min annealing in vacuum applied in the present study, the Ta barrier fails after annealing at $500^{\circ} \mathrm{C}$. An amorphous $\mathrm{Ta}_{74} \mathrm{Si}_{26}$ thin film improves the performance by raising the failure temperature of a $\langle\mathrm{Si}\rangle / \mathrm{Ta}_{74} \mathrm{Si}_{26}(100 \mathrm{~nm}) /$ $\mathrm{Cu}(500 \mathrm{~nm})$ metallization to $650^{\circ} \mathrm{C}$. Unparalled results are obtained with an amorphous ternary $\mathrm{Ta}_{36} \mathrm{Si}_{14} \mathrm{~N}_{50}$ thin film in the $\mathrm{Si} / \mathrm{Ta}_{36} \mathrm{Si}_{14} \mathrm{~N}_{50}(120 \mathrm{~nm}) / \mathrm{Cu}(500 \mathrm{~nm})$ and in the $\mathrm{Si} / \mathrm{TiSi}_{2}(30 \mathrm{~nm}) / \mathrm{Ta}_{36} \mathrm{SiN}_{50}(80 \mathrm{~nm}) / \mathrm{Cu}(500 \mathrm{~nm})$ metallization that break down only after annealing at $900^{\circ} \mathrm{C}$. The failure is induced by a premature crystallization of the $\mathrm{Ta}_{36} \mathrm{Si}_{14} \mathrm{~N}_{50}$ alloy (whose crystallization temperature exceeds $1000^{\circ} \mathrm{C}$ ) when in contact with copper.
\end{abstract}

\section{INTRODUCTION}

Stable, uniform, and reproducible contacts are essential for a successful device performance. Aluminum, commonly used in VLSI technology for contacts and interconnections, is highly reactive with silicon as well as with silicides. Because of the electromigration problems of aluminum-based interconnection lines, metals other than $\mathrm{Al}$ are being evaluated for VLSI applications. Copper has a lower electrical resistivity and a higher resistance to electromigration than $\mathrm{Al}$. On the other hand, $\mathrm{Cu}$ is known to be very mobile in metals and semiconductors even at quite modest temperatures, so that very effective diffusion barriers are necessary to prevent $\mathrm{Cu}$ diffusion and intermixing into silicon. ${ }^{1-3}$ Because amorphous alloys lack grain boundaries that can act as fast diffusion paths, they may offer attractive alternatives to polycrystalline thin films as diffusion barriers, especially for copper. ${ }^{4-9} \mathrm{We}$ report on properties of $\mathrm{Ta}$, amorphous $\mathrm{Ta}_{74} \mathrm{Si}_{26}$ and amorphous $\mathrm{Ta}_{36} \mathrm{Si}_{14} \mathrm{~N}_{50}$ alloy thin films and compare them as diffusion barriers between $\mathrm{Cu}$ and $\mathrm{Si}$. Rutherford backscattering spectrometry, $x$-ray diffraction and cross-sectional transmission electron microscopy are used to evaluate the barrier performance in combination with electrical measurements on planar diodes with shallow $n^{+} p$ junctions. The last method is the most sensitive and relevant test to evaluate the effectiveness of barriers.

\section{EXPERIMENTAL PROCEDURES}

Substrates of $\langle 111\rangle$ oriented $5 \Omega \mathrm{cm} n$-type silicon were used throughout this experiment to deposit the unpatterned samples for all tests other than for electrical evaluations. The substrates for $I(V)$ measurements were $\langle 100\rangle$ Si wafers with As ${ }^{+}$implanted shallow junction $n+p$ diodes. The junction depth is $300 \mathrm{~nm}$, the As surface concentration is approximately $10^{21} \mathrm{~cm}^{-3}$, and the contact area is large (about $230 \times 230 \mu \mathrm{m}^{2}$ ). The contact metallizations were formed by blanket depositions and delineated by lift-off. Prior to loading into the deposition chamber, the silicon wafers were etched with diluted HF.

All depositions were performed in an rf sputtering system. A base pressure of $3 \times 10^{-7}$ Torr was achieved using a cryopump and a cryogenic baffle. A magnetron-type circular cathode, $7.5 \mathrm{~cm}$ in diameter, was used as the sputtering source. The substrate holder was placed about $7 \mathrm{~cm}$ below the target and was neither cooled nor heated externally. Tantalum and $\mathrm{Ta}_{74} \mathrm{Si}_{26}$ films were deposited in $\mathrm{Ar}$ using $\mathrm{Ta}$ and $\mathrm{Ta}_{5} \mathrm{Si}_{3}$ targets, respectively. The $\mathrm{Ta}_{36} \mathrm{Si}_{14} \mathrm{~N}_{50}$ film was deposited by reactive sputtering of the same $\mathrm{Ta}_{5} \mathrm{Si}_{3}$ target in an $\mathrm{Ar} / \mathrm{N}_{2}$ gas mixture. The flow ratios of Ar to $\mathrm{N}_{2}$ and the total gas pressure were adjusted by mass flow controllers and monitored with a capacitive manometer in a feedback loop. All tantalum, tantalum silicide, and $\mathrm{Ta}_{36} \mathrm{Si}_{14} \mathrm{~N}_{50}$ films were sputtered with $10 \mathrm{~m}$ Torr total gas pressure and $300 \mathrm{~W}$ forward sputtering power. In some cases, a $\mathrm{TiSi}_{2}$ contacting layer was deposited by sputtering from a $\mathrm{TiSi}_{2}$ target prior to the $\mathrm{Ta}_{36} \mathrm{Si}_{14} \mathrm{~N}_{50}$ deposition. The metallizations were completed without breaking the vacuum by adding a 500 -nm-thick (or $250-300-\mathrm{nm}$ thick) copper layer over the tantalum-based films sputtered from a copper target in pure Ar with 5 mTorr total gas pressure, a forward sputtering power of $300 \mathrm{~W}$, and a substrate bias of $-50 \mathrm{~V}$. After patterning by lift-off, if applicable, the samples were annealed in a vacuum furnace at pressure of about $5 \times 10^{-7}$ Torr and temperatures ranging from 500 to $950^{\circ} \mathrm{C}$. All annealings lasted $30 \mathrm{~min}$. The stability of the metallizations were determined by 2 $\mathrm{MeV}{ }^{4} \mathrm{He}$ backscattering spectrometry, x-ray diffraction, cross-sectional transmission electron microscopy, scanning electron microscopy and $I(V)$ measurements of the $n^{+} p$ shallow junction diodes.

\section{RESULTS AND DISCUSSION}

The $\langle\mathrm{Si}\rangle / \mathrm{Cu}$ system is very unstable. The shallow junction diodes with $\langle\mathrm{Si}\rangle / \mathrm{Cu}$ metallization are shorted already after annealing at $300^{\circ} \mathrm{C}$ (Fig. 1). This failure is 


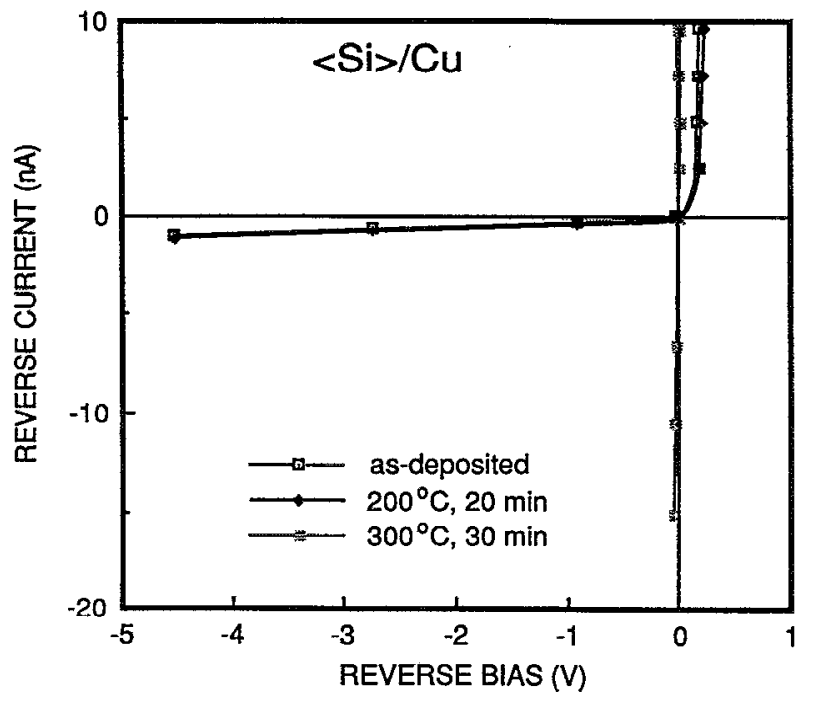

FIG. 1. The $I-V$ characteristics of a shallow $n^{+} p$ junction with a $\langle\mathrm{Si}\rangle /$ $\mathrm{Cu}(500 \mathrm{~nm})$ metallization as a function of temperature for $30 \mathrm{~min}$ vacuum annealing. The contact area is about $230 \times 230 \mu \mathrm{m}^{2}$.

induced by a very deep, laterally nonuniform penetration of copper into the silicon accompanied by the formation of the $\mathrm{Cu}_{3} \mathrm{Si}$ and $\mathrm{CuO}$ phase. The surface morphology is very rough after annealing as can be seen in Fig. 2.

Figure 3 shows the backscattering spectra of a $\langle\mathrm{Si}\rangle /$ $\mathrm{Ta}(180 \mathrm{~nm}) / \mathrm{Cu}(260 \mathrm{~nm})$ sample as-deposited and annealed at 600 and $650^{\circ} \mathrm{C}$. The tantalum film contains about 3 at. \% argon and below 3 at. \% oxygen as determined by backscattering spectrometry on films deposited on carbon. After annealing at $600^{\circ} \mathrm{C}$ the low-energy edge of tantalum signal indicates a slight interaction between tantalum and silicon. After annealing at $650^{\circ} \mathrm{C}$, a small amount of tantalum is present on the surface of the sample and a clear step in the Si signal appears. This observed evolution of the spectrum can be explained by a $\mathrm{TaSi}_{2}$ formation, which is confirmed by $x$-ray diffraction results. In addition to $\mathrm{TaSi}_{2}, \mathrm{a} \mathrm{Cu}_{3} \mathrm{Si}$ phase was also detected by $\mathrm{x}$-ray diffraction. According to the scanning electron microscopy study, the

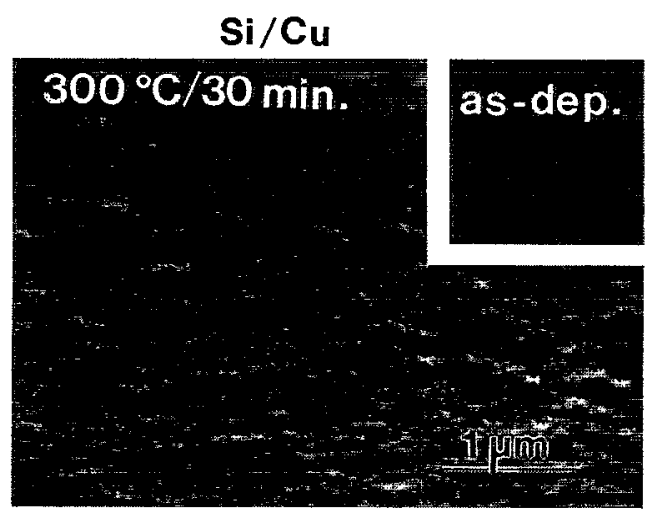

FIG. 2. Scanning electron micrographs of the surface of a typical $n^{+} p$ (Si) $/ \mathrm{Cu}(500 \mathrm{~nm}$ ) shallow junction diode as-deposited (right corner inset) and annealed at $300^{\circ} \mathrm{C}$ for $30 \mathrm{~min}$ in vacuum.

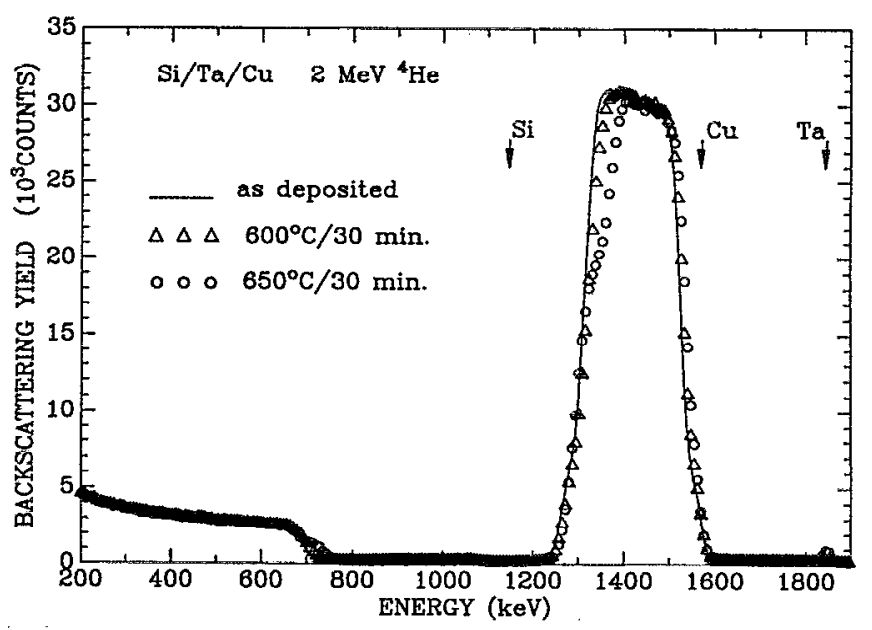

FIG. 3. $2.0 \mathrm{MeV} 4 \mathrm{He}^{++}$backscattering spectra of a $\langle\mathrm{Si}\rangle / \mathrm{Ta}(180 \mathrm{~nm}) /$ $\mathrm{Cu}(260 \mathrm{~nm})$ sample before and after vacuum annealing at 600 and $650{ }^{\circ} \mathrm{C}$ for $30 \mathrm{~min}$. The He beam is incident at an angle of $7^{\circ}$ from the sample normal; the scattering angle of detected particles is $170^{\circ}$.

$550^{\circ} \mathrm{C}$ annealing does not induce changes in the sample morphology, the surface looks smooth and free of defects.

The electrical tests on shallow junction diodes with $\langle\mathrm{Si}\rangle / \mathrm{Ta}(180 \mathrm{~nm}) / \mathrm{Cu}(500 \mathrm{~nm})$ metallization shows that the failure of the metallization takes place at significantly lower temperatures than observed by backscattering spectrometry or scanning electron microscopy (Fig. 4). After annealing at $500{ }^{\circ} \mathrm{C}$ the reverse leakage current of the diodes increases significantly from 0.2 to $8 \mathrm{nA}$ at $-1 \mathrm{~V}$. Diodes annealed at $550^{\circ} \mathrm{C}$ are shorted. Our backscattering spectrometry results are in good agreement with backscattering studies by Holloway et al., ${ }^{10,11}$ which claim that Ta prevents $\mathrm{Cu}-\mathrm{Si}$ interaction up to $600^{\circ} \mathrm{C}$. The results presented here clearly indicate that the electrical test on shallow junctions is far more sensitive than backscattering

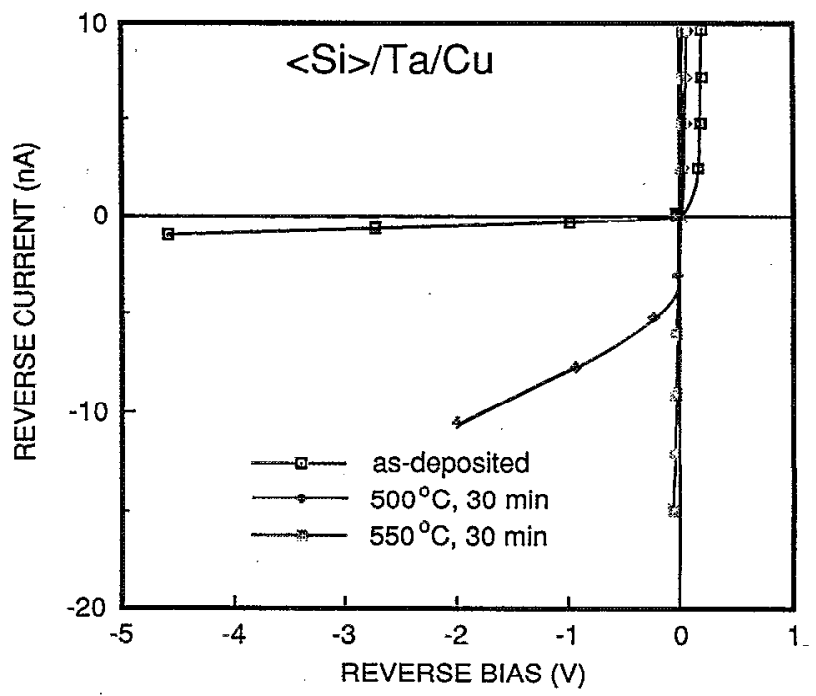

FIG. 4. The $I-V$ characteristics of a shallow $n^{+} p$ junction with the $\langle\mathrm{Si}\rangle /$ $\mathrm{Ta}(180 \mathrm{~nm}) / \mathrm{Cu}(500 \mathrm{~nm})$ metallization as a function of temperature for $30 \mathrm{~min}$ vacuum annealing. The contact area is about $230 \times 230 \mu \mathrm{m}^{2}$. 


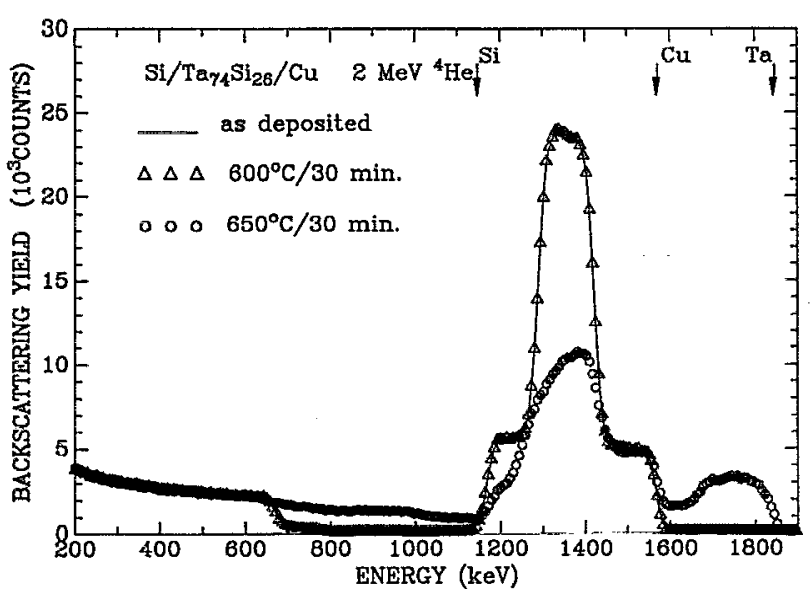

FIG. 5. $2.0 \mathrm{MeV} 4 \mathrm{He}^{++}$backscattering spectra of a $\langle\mathrm{Si}\rangle / \mathrm{Ta}_{74} \mathrm{Si}_{26}(100$ $\mathrm{nm}) / \mathrm{Cu}(360 \mathrm{~nm})$ sample before and after vacuum annealing at 600 and $650^{\circ} \mathrm{C}$ for $30 \mathrm{~min}$. The He beam is incident at an angle of $7^{\circ}$ from the sample normal; the scattering angle of detected particles is $170^{\circ}$.

spectrometry and should always be included to properly evaluate diffusion barriers for metal/semiconductor contact applications. Although $\mathrm{Ta}$ and $\mathrm{Cu}$ do not form compounds, enough copper diffuses through grain boundaries and defects in the tantalum layer into silicon substrate to cause the failure of the shallow junction diodes before being detected by backscattering spectrometry. This result agrees with the general statement that elemental metals are not good diffusion barriers. ${ }^{3}$ Rather, their effectiveness is directly related to the level of impurities, like oxygen or nitrogen, they contain.

To look for improvements, one material that readily comes to mind is tantalum silicide. This material offers an advantage over pure $T a$ in that it can be deposited in an amorphous phase and, additionally, is thermodynamically stable with $\mathrm{Si}$.

The composition of tantalum silicide used in this study is $\mathrm{Ta}_{74} \mathrm{Si}_{26}$. This film is amorphous with a crystallization temperature of about $850^{\circ} \mathrm{C}$. The resistivity of a $120 \mathrm{~nm}$ $\mathrm{Ta}_{74} \mathrm{Si}_{26}$ film is $265 \mu \Omega \mathrm{cm}$. The impurity level is about 3 at. $\%$ of argon and 5 at. $\%$ of oxygen. Figure 5 shows the backscattering spectra of the $\langle\mathrm{Si}\rangle / \mathrm{Ta}_{74} \mathrm{Si}_{26}(100 \mathrm{~nm}) /$ $\mathrm{Cu}(360 \mathrm{~nm})$ sample before and after annealing at 600 and $650^{\circ} \mathrm{C}$. Within the resolution of backscattering spectrometry, the structure does not change during annealing at $600^{\circ} \mathrm{C}$. The spectrum collected after annealing at $650^{\circ} \mathrm{C}$ indicates that the sample is laterally nonuniform, with tantalum present on the surface. Electrical tests of the $\mathrm{Ta}_{74} \mathrm{Si}_{26}$ diffusion barrier on shallow junction diodes with the $\langle\mathrm{Si}\rangle / \mathrm{Ta}_{74} \mathrm{Si}_{26}(100 \mathrm{~nm}) / \mathrm{Cu}(500 \mathrm{~nm})$ metallization agree well with the backscattering data (Fig. 6). The reverse leakage current of the diodes remains almost unchanged after annealing at $600^{\circ} \mathrm{C}$ and diodes are shorted after annealing at $650^{\circ} \mathrm{C}$. No new phases were detected in the annealed samples by $\mathrm{x}$-ray diffraction, in accordance with another study that finds that $\mathrm{Cu}$ and tantalum silicide form a thermodynamically stable system and do not react with each other. ${ }^{12}$ The failure mechanism of the $\mathrm{Si} / a$ -

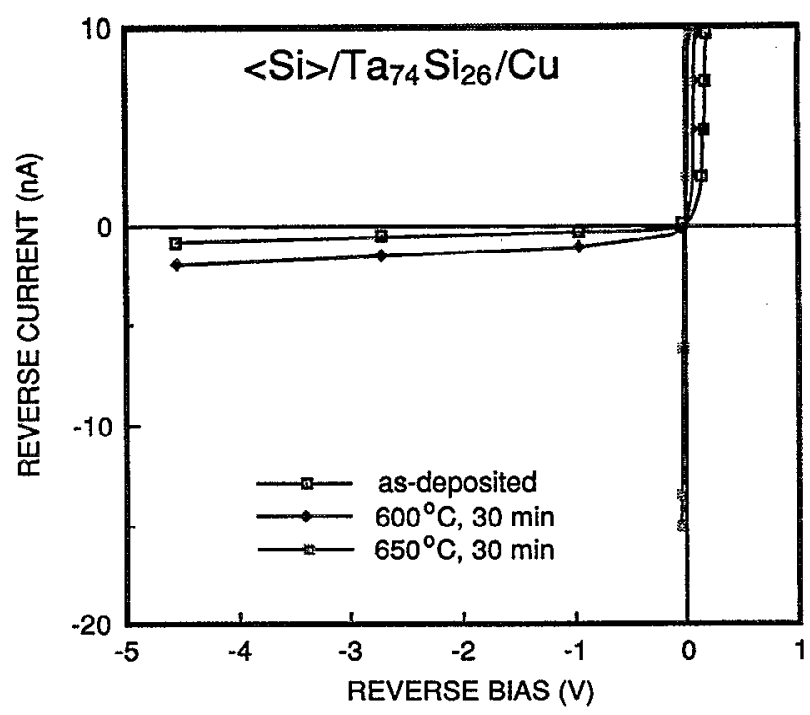

FIG. 6. The $I-V$ characteristics of a shallow $n^{+} p$ junction with the $\langle\mathrm{Si}\rangle / \mathrm{Ta}_{74} \mathrm{Si}_{26}(100 \mathrm{~nm}) / \mathrm{Cu}(500 \mathrm{~nm})$ metallization as a function of temperature for $30 \mathrm{~min}$ vacuum annealing. The contact area is about $230 \times 230 \mu \mathrm{m}^{2}$.

$\mathrm{Ta}_{74} \mathrm{Si}_{26} / \mathrm{Cu}$ system is a subject of current study.

The stability of the $\mathrm{Si} / \mathrm{Cu}$ metallization can be further improved by using an amorphous $\mathrm{Ta}_{36} \mathrm{Si}_{14} \mathrm{~N}_{50}$ thin-film diffusion barrier. An alloy of this particular atomic composition was chosen because of its superior barrier performance between aluminum and silicon. ${ }^{13}$ The film contains about 3 at. $\%$ argon and below 3 at. \% oxygen, as measured by backscattering spectrometry with samples deposited on carbon. The resistivity of the as-deposited $\mathrm{Ta}_{36} \mathrm{Si}_{14} \mathbf{N}_{50}$ film is about $625 \mu \Omega \mathrm{cm}$. The structure of the as-deposited film is amorphous by both $x$-ray and electron diffraction. On a sapphire substrate, $T_{36} \mathrm{Si}_{14} \mathrm{~N}_{50}$ crystallizes after $2 \mathrm{~h}$ annealing in vacuum at $1100^{\circ} \mathrm{C}$. The crystallization product is a mixture of hexagonal $\mathrm{Ta}_{2} \mathrm{~N}$, tetragonal $\mathrm{Ta}_{5} \mathrm{Si}_{3}$ and hexagonal $\mathrm{Ta}_{3}\left(\mathrm{Ta}_{0.28} \mathrm{Si}_{0.72}\right)$. Such a high crystallization temperature of the $\mathrm{Ta}_{36} \mathrm{Si}_{14} \mathrm{~N}_{50}$ is expected, based on the idea that the crystallization temperature is higher for the transition metal-metalloid alloys when transition metal has high outer electron concentration (e.g., $\mathrm{W}$ or Ta).$^{14}$

The $I(V)$ characteristics of shallow junction diodes with the $\langle\mathrm{Si}\rangle / \mathrm{Ta}_{36} \mathrm{Si}_{14} \mathrm{~N}_{50}(120 \mathrm{~nm}) / \mathrm{Cu}(500 \mathrm{~nm})$ were measured before and after annealings (Fig. 7). After a $900{ }^{\circ} \mathrm{C}$ annealing the reverse leakage current of some of the diodes at $-1 \mathrm{~V}$ increases from 0.4 to about $5 \mathrm{nA}$. The diodes annealed at $950^{\circ} \mathrm{C}$ are shorted. The backscattering spectrum of the $\langle\mathrm{Si}\rangle / \mathrm{Ta}_{36} \mathrm{Si}_{14} \mathrm{~N}_{50}(120 \mathrm{~nm}) / \mathrm{Cu}(280 \mathrm{~nm})$ sample annealed at $900^{\circ} \mathrm{C}$ is the same as the spectrum of the as-deposited sample. The spectrum of the sample annealed at $950{ }^{\circ} \mathrm{C}$ indicates interactions between the layers.

To understand the behavior of the $\langle\mathrm{Si}\rangle / \mathrm{Ta}_{36} \mathrm{Si}_{14} \mathrm{~N}_{50} / \mathrm{Cu}$ sample during heat treatment, crosssection transmission electron microscopy was used to investigate the reactions between the layers. Figure 8 shows the cross-sectional micrographs of $\langle\mathrm{Si}\rangle / \mathrm{Ta}_{36} \mathrm{Si}_{14} \mathrm{~N}_{50}(150$ $\mathrm{nm}) / \mathrm{Cu}$ samples as-deposited and after annealing at 850 , 


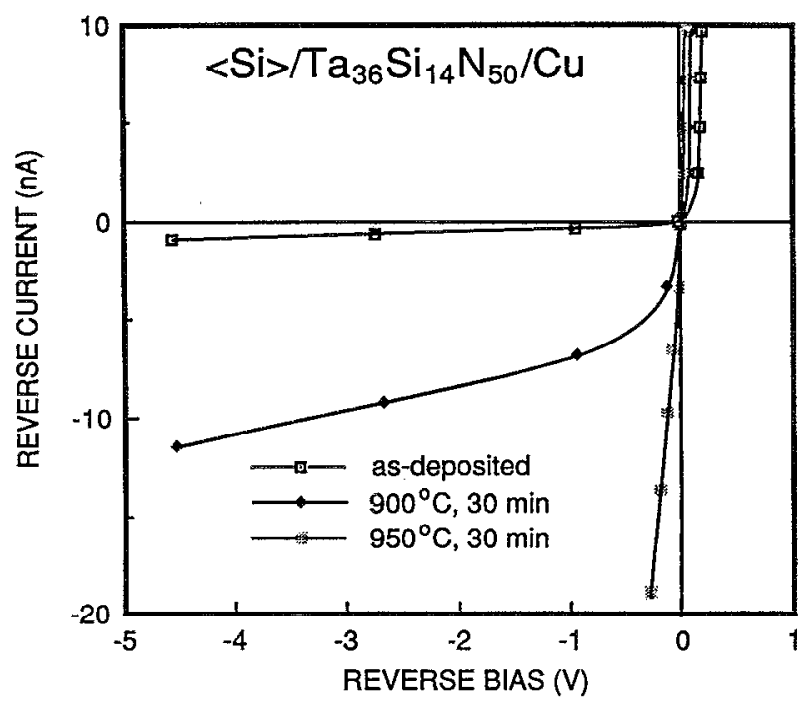

FIG. 7. The $I-V$ characteristics of a shallow $n^{+} p$ junction with the $\langle\mathrm{Si}\rangle / \mathrm{Ta}_{36} \mathrm{Si}_{14} \mathrm{~N}_{50}(120 \mathrm{~nm}) / \mathrm{Cu}(500 \mathrm{~nm})$ metallization as a function of temperature for $30 \mathrm{~min}$ vacuum annealing. The contact area is about $230 \times 230 \mu \mathrm{m}^{2}$.

900 , or $950^{\circ} \mathrm{C}$. The micrographs of the as-deposited sample show three distinct layers with sharp interfaces. The $\mathrm{Ta}_{36} \mathrm{Si}_{14} \mathrm{~N}_{50}$ layer is amorphous. A sample annealed at $850^{\circ} \mathrm{C}$ is unchanged with the $\mathrm{Ta}_{36} \mathrm{Si}_{14} \mathrm{~N}_{50}$ remaining amorphous. The interaction between the layers starts during the $900{ }^{\circ} \mathrm{C}$ heat treatment. A new polycrystalline phase begins

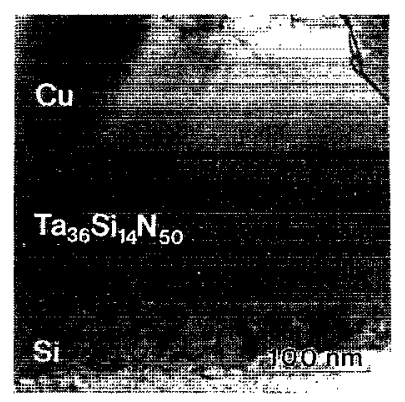

as-dep

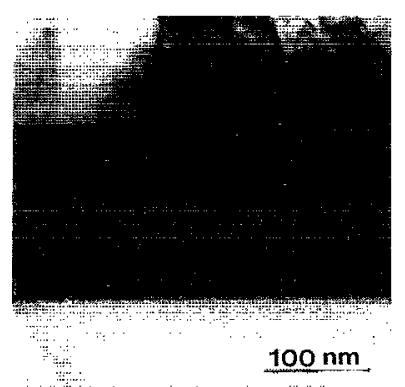

$850^{\circ} \mathrm{C}$

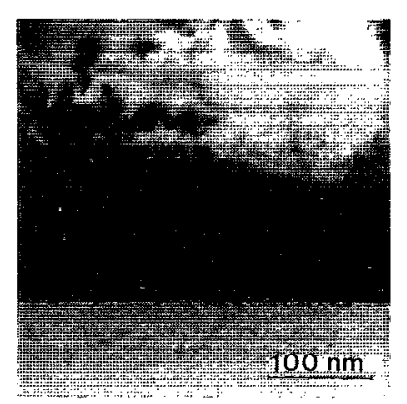

$900^{\circ} \mathrm{C}$

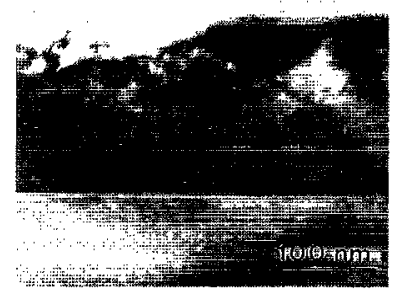

$950^{\circ} \mathrm{C}$
FIG. 8. The cross-sectional transmission electron micrographs of the (Si)/ $\mathrm{Ta}_{36} \mathrm{Si}_{14} \mathrm{~N}_{50}(150 \mathrm{~nm}) / \mathrm{Cu}(380 \mathrm{~nm}$ ) samples before and after vacuum annealing at 850,900 , and $950^{\circ} \mathrm{C}$ for $30 \mathrm{~min}$. to form at the $\mathrm{Cu}$ and $\mathrm{Ta}_{36} \mathrm{Si}_{14} \mathrm{~N}_{50}$ interface. The average thickness of this layer is about $20 \mathrm{~nm}$ and has some slight lateral nonuniformity. After annealing at $950^{\circ} \mathrm{C}$, a laterally uniform layer remains of the amorphous diffusion barrier that is only about $50 \mathrm{~nm}$ thick, (1/3 of the initial thickness). The thickness of the new polycrystalline layer has increased to $100 \mathrm{~nm}$. Electron diffraction data of the asdeposited $\langle\mathrm{Si}\rangle / \mathrm{Ta}_{36} \mathrm{Si}_{14} \mathrm{~N}_{50} / \mathrm{Cu}$ planar sample show $\mathrm{Cu}$ rings and one diffuse ring associated with the amorphous $\mathrm{Ta}_{36} \mathrm{Si}_{14} \mathrm{~N}_{50}$ layer. After annealing at $950^{\circ} \mathrm{C}$ that ring and those of $\mathrm{Cu}$ are still present but additional lines corresponding to the $\mathrm{Ta}_{5} \mathrm{Si}_{3}$ phase show up. It appears that in contact with polycrystalline copper layer, the crystallization temperature of amorphous $\mathrm{Ta}_{36} \mathrm{Si}_{14} \mathrm{~N}_{50}$ drops from $1100^{\circ} \mathrm{C}$, the crystallization temperature of the layer deposited on sapphire, to $900^{\circ} \mathrm{C}$. That the interface with a polycrystalline layer can induce the accelerated crystallization of an amorphous alloy is well known. ${ }^{15-19}$

The accelerated crystallization of the $\mathrm{Ta}_{36} \mathrm{Si}_{14} \mathrm{~N}_{50}$ alloy in contact with a $\mathrm{Cu}$ layer can be explained in various ways. (1) The outdiffusion of Si from the $\mathrm{Ta}_{36} \mathrm{Si}_{14} \mathrm{~N}_{50}$ film into the $\mathrm{Cu}$ layer significantly lowers the crystallization temperature by depleting the alloy of Si. The solubility of $\mathrm{Si}$ in $\mathrm{Cu}$ is about $5 \%$ at $850^{\circ} \mathrm{C}$. We did not detect $\mathrm{Cu}-\mathrm{Si}$ compounds by $\mathrm{x}$-ray or electron diffraction, but it is possible that their quantity is below the detection limit of the methods. (2) The diffusion of $\mathrm{Cu}$ into the amorphous $\mathrm{Ta}_{36} \mathrm{Si}_{14} \mathrm{~N}_{50}$ alloy that forms a quarternary amorphous phase with a lowered crystallization temperature is also conceiveable, but less likely than diffusion of $\mathrm{Si}$ into $\mathrm{Cu}$ because the diffusivity of $\mathrm{Cu}$ in the $\mathrm{Ta}_{36} \mathrm{Si}_{14} \mathrm{~N}_{50}$ is expected to be very low. (3) The interface with the polycrystalline $\mathrm{Cu}$ provides sites with a lowered nucleation barrier for the amorphous $\mathrm{Ta}_{36} \mathrm{Si}_{14} \mathrm{~N}_{50}$; the crystallization process then propagates uniformly through the amorphous layer.

The preceeding results show that the failure of the $\mathrm{Si} / \mathrm{Ta}_{36} \mathrm{Si}_{14} \mathrm{~N}_{50} / \mathrm{Cu}$ metallization can be explained in terms of a laterally uniform decay of the $\mathrm{Ta}_{36} \mathrm{Si}_{14} \mathrm{~N}_{50}$ film associated with its accelerated crystallization. Once fully crystallized, the rapid diffusion of copper into silicon substrate through the grain boundaries presumably takes over and destroys the junction. The $\mathrm{Ta}_{36} \mathrm{Si}_{14} \mathrm{~N}_{50}$ apparently functions as a sacrificial barrier between $\mathrm{Si}$ and $\mathrm{Cu}$. It should thus be possible to increase the time to failure or the failure temperature of the metallization by increasing the thickness of the barrier.

In a practical application, a contacting layer should be added to the $\langle\mathrm{Si}\rangle / \mathrm{Ta}_{36} \mathrm{Si}_{14} \mathrm{~N}_{50} / \mathrm{Cu}$ metallization. Since $\mathrm{TiSi}_{2}$ is used in industry, we tested the stability of a $\langle\mathrm{Si}\rangle / \mathrm{TiSi}_{2}(30 \mathrm{~nm}) / \mathrm{Ta}_{36} \mathrm{Si}_{14} \mathrm{~N}_{50}(80 \mathrm{~nm}) / \mathrm{Cu}(500 \mathrm{~nm})$ metallization deposited on the shallow junction diodes. Figure 9 shows the $I(V)$ characteristics of the diodes before and after annealing at 900 or $950^{\circ} \mathrm{C}$. The reverse current does not change after annealing at $900^{\circ} \mathrm{C}$, and increases about six fold after annealing at $950^{\circ} \mathrm{C}$. The failure temperature of the $\langle\mathrm{Si}\rangle / \mathrm{TiSi}_{2} / \mathrm{Cu}$ system is about $300^{\circ} \mathrm{C} .^{17}$ 


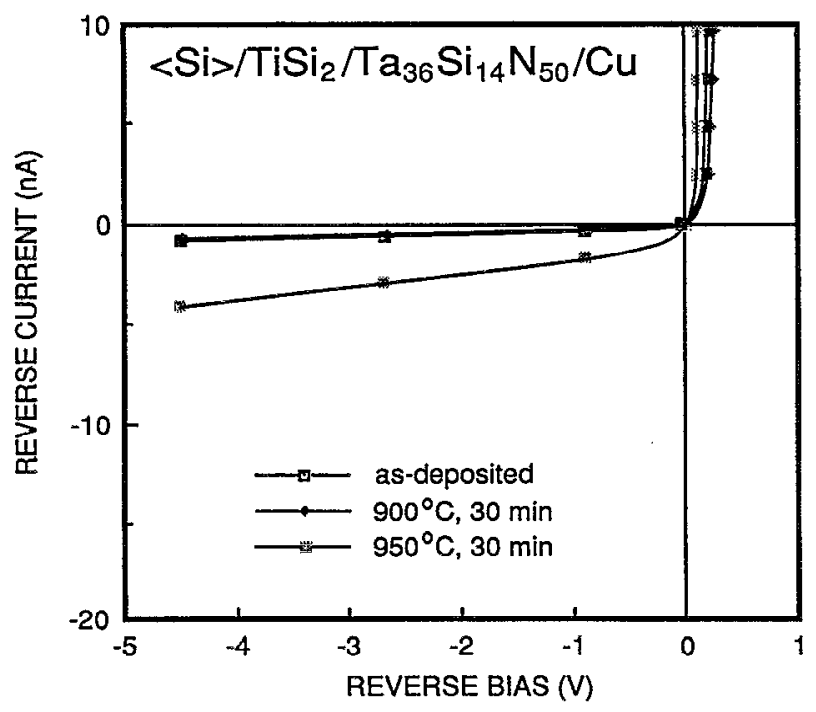

FIG. 9. The $I-V$ characteristics of a shallow $n^{+} p$ junction with the (Si) $/ \mathrm{TiSi}_{2}(30 \mathrm{~nm}) / \mathrm{Ta}_{36} \mathrm{Si}_{14} \mathrm{~N}_{50}(120 \mathrm{~nm}) / \mathrm{Cu}(500 \mathrm{~nm})$ metallization before and after vacuum annealing at 900 and $950{ }^{\circ} \mathrm{C}$ for $30 \mathrm{~min}$. The contact area is $230 \times 230 \mu \mathrm{m}^{2}$.

\section{CONCLUSIONS}

The results presented here convincingly show that an amorphous $\mathrm{Ta}_{36} \mathrm{Si}_{14} \mathrm{~N}_{50}$ film is a very effective diffusion barrier between copper and silicon. The effectiveness of this barrier seems to be attributable to the facts that the $\mathrm{Ta}_{36} \mathrm{Si}_{14} \mathrm{~N}_{50}$ alloy is amorphous, and is chemically inert with copper. As an amorphous alloy, $\mathrm{Ta}_{36} \mathrm{Si}_{14} \mathrm{~N}_{50}$ lacks grain boundaries that can act as fast diffusion paths. It is likely that bulk diffusivity of $\mathrm{Cu}$ in this alloy is very low. Also, copper does not react with tantalum and nitrogen, which make up $86 \%$ of the barrier's elements and minimizes the driving force for chemical reactions.

\section{ACKNOWLEDGMENTS}

The authors wish to thank R. Gorris and B. Stevens for technical assistance, R. Ruiz of the Jet Propulsion Laboratory for SEM analyses and R. Sampley for assistance in manuscript preparation. This work was sponsored in part by the Army Research Office under subcontract DAAL0389-K-0049, whose support is acknowledged. A graduate fellowship award by the AMOCO foundation is gratefully acknowledged by J. S. Reid, and P. J. Pokela thanks the Academy of Finland for a fellowship.

${ }^{1}$ M-A. Nicolet, Thin Solid Films 54, 415 (1978).

${ }^{2}$ M. Wittmer, J. Vac. Sci. Technol. A 2, 273 (1984).

${ }^{3}$ H. P. Kattelus and M-A. Nicolet, Diffusion Phenomena in Thin Films and Microelectronic Materials, edited by D. Gupta and P. S. Ho (Noyes Publications, 1988).

${ }^{4}$ J. D. Wiley, J. H. Perepezko, J. E. Nordman, and K-J. Guo, IEEE Trans. Ind. Electron. 29 (1982).

${ }^{5}$ M-A. Nicolet, I. Suni, and M. Finetti, Solid State Technol. 26, 129 (1983).

${ }^{6}$ L. S. Hung, F. W. Saris, S. Q. Wang, and J. W. Mayer, J. Appl. Phys. 59, 2416 (1986).

${ }^{7}$ S. E. Hornstrom, T. Lin, O. Thomas, P. M. Fryer, and J. M. E. Harper, J. Vac. Sci. Technol. A 6, 1650 (1988).

${ }^{8}$ S. Q. Wang and J. W. Mayer, J. Appl. Phys. 65, 1957 (1989).

${ }^{9}$ H. P. Kattelus, E. Kolawa, and M-A. Nicolet, J. Vac Sci. Technol. A 3, 507 (1985).

${ }^{10} \mathrm{~K}$. Holloway and P. M. Fryer, Appl. Phys. Lett. 57, 1736 (1990).

${ }^{11}$ K. Holloway and P. M. Fryer, MRS Proc. 181, 41 (1990).

${ }^{12}$ J. Reid, E. Kolawa, and M-A. Nicolet (to be published).

${ }^{13}$ E. Kolawa, J. Molarius, C. W. Nieh, and M-A. Nicolet, J. Vac. Sci. Technol. A 8, 3006 (1990).

${ }^{14}$ T. Yoshitake, Y. Kubo, and H. Igarashi, Mater. Sci. Eng. 97, 269 (1988).

${ }^{15}$ R. E. Thomas, J. H. Perepezko, and J. D. Wiley, Appl. Surf. Sci. 26, 534 (1986)

${ }^{16}$ E. A. Dobisz, B. L. Doyle, J. H. Perepezko, J. D. Wiley, and P. S Pearcy, MRS Proc. 37, 479 (1984).

${ }^{17}$ R. E. Thomas, J. H. Perepezko, and J. D. Wiley, MRS Proc. 54, 127 (1985).

${ }^{18}$ U. Koster, Mater. Sci. Eng. 97, 233 (1988).

${ }^{19}$ C. A. Chang and C. K. Hu, Appl. Phys. Lett. 57, 617 (1990). 